\title{
A Historical Review of Classic Publications in Web of Science Category of Obstetrics and Gynecology
}

\author{
Su-Yen Wu${ }^{1}$, Wen-Ta Chiu ${ }^{1 *}$, Yuh-Shan $\mathrm{Ho}^{2 *}$ \\ ${ }^{1}$ AHMC HealthSysmtem, 500 East Main Street, Alhambra, CA 91801, USA. \\ ${ }^{2}$ Trend Research Centre, Asia University, No. 500, Lioufeng Road, Wufeng, Taichung County 41354, Taiwan.
}

*Corresponding Author: Yuh-Shan Ho, Trend Research Centre, Asia University, Taichung County 41354, Taiwan.

Received: 24 July 2021 | Accepted: 03 September 2021 | Published: 11 September 2021

Citation: Su-Y Wu, Wen-T Chiu, Yuh-S Ho. (2021 A Historical Review of Classic Publications in Web of Science Category of Obstetrics and Gynecology. Journal of Clinical and Laboratory Research. 3(4); DOI:10.31579/2768-0487/040

Copyright: (C) 2021 Yuh-Shan Ho. This is an open-access article distributed under the terms of the Creative Commons Attribution License, which permits unrestricted use, distribution, and reproduction in any medium, provided the original author and source are credited.

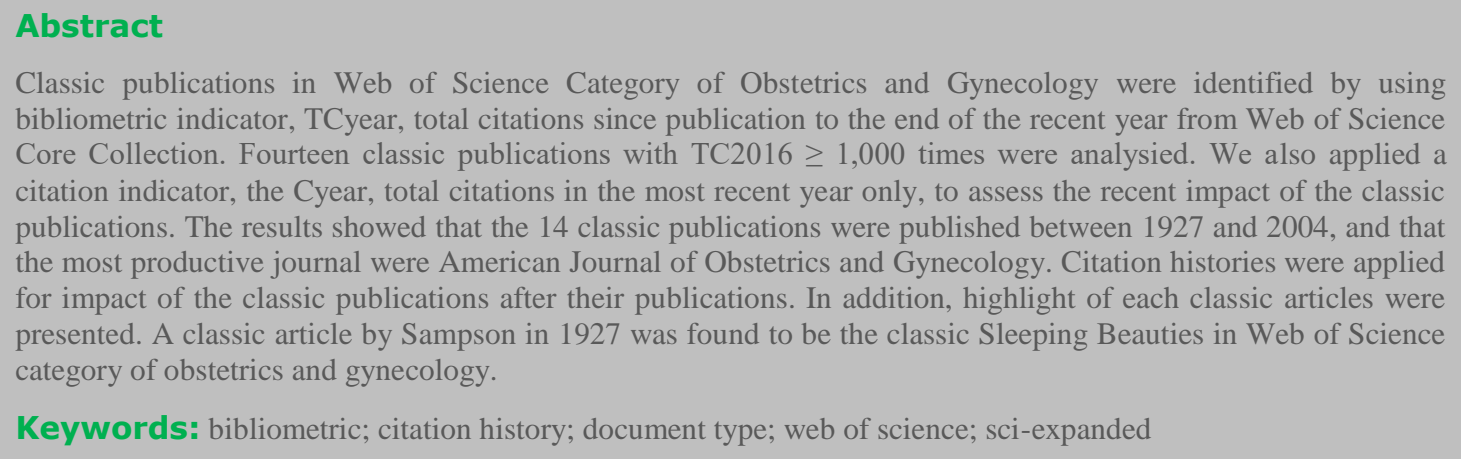

\section{Introduction}

It has been reported that due to the presence of many most cited papers, there have been influential subsequent advances in molecular biology resulting in helping a great number of people (Picknett and Davis 1999). Highly cited articles nevertheless provide an interesting and useful insight into which authors, articles, and topics are influencing the research profession over time (Smith 2008). The most notable studies can be usefulness as tools for teaching, advocating, and championing the contribution of research (Levitt et al. 2015). In 1970s, articles have been cited 100 or more times were called 'classic articles' (Garfield 1976). Garfield (1976) pointed that classic methods, the starting points of great scientific advances, and identified with eponymic terminology were normally presented in classic articles. In last two decades, number of journals in Science Citation Index Expanded increased from 4,962 journals in 1997 to 8,879 journals in 2016. Thus, higher citations at publication years were likely to be published in recent years (Ho 2014a). Articles with at least 1,000 citations from Web of Science Core Collection were also named classic articles in for example, Web of Science categories of surgery (Long et al. 2014), psychology (Ho and Hartley 2016a), and neurosciences (Yeung and Ho 2018), as well as in a country such as USA (Ho and Hartley 2016b) and Taiwan (Ho 2018).

In this study, we analysed classic articles in Web of Science category of obstetrics and gynecology by comparing their total citations from Web of
Science Core Collection from 1900 to 2016. We report on (1) what are the characteristics of classic papers - including publication years, journals, and document types; (2) what are the classic articles about; and (3) the life citation cycles and attributes of the classic articles.

\section{Methodology}

The data reported in this study were retrieved from the online version of Science Citation Index Expanded (SCI-EXPANDED) the Clarivate Analytics (formerly known as the Thomson Reuters and the Institute for Scientific Information) Web of Science Core Collection database. According to Journal Citation Reports (JCR) of 2016 (InCites Journal Citation Reports dataset updated September 09, 2017), it indexes 8,879 journals with citation references across $177 \mathrm{Web}$ of Science categories in SCI-EXPANDED. In total 493,689 documents (including 309,377 articles) were found in Web of Science category of obstetrics and gynecology within the publication year from 1900 to 2016 based on SCIEXPANDED (updated on April 23, 2018).

Two citation indicators TCyear and Cyear were employed to characterize the classic articles. TCyear is the total number citations from Web of Science Core Collection since publication to the end of the most recent year (Wang et al. 2011, Chuang et al. 2011). Cyear is the number of citations in the most recent year. C2016 means the number of citation in 2016 (Ho 2012). TCyear $\geq 1,000$ was used to retrieve the classic articles 
(Long et al. 2014; Ho and Hartley 2016a,b; Ho 2018). We downloaded all records and number of citations for each article for each year into spreadsheet software, and manipulated them using Microsoft Excel 2016 (Li and Ho 2008; Ho and Fu 2016). In addition, all hard copies of the 14 classic publications were found to check analysis information.

\section{Results and Discussion}

\section{Document types, languages of publication, and authors}

Documnt types and languages of publication were basic analysis for publications in a research field (Hsieh et al. 2004). A total of 14 classic publications $(0.0028 \%$ of 493,689 documents) with TC2016 $\geq 1,000$ in Web of Science category of obstetrics and gynecology were found within three document types indexed in the Web of Science. All classic documents were published in English. Thirty classic publications were found to be document type of article including one of them was belong to both document types of article and proceedings paper. One was published as document type of review. A classic review entitled "Report of the National High Blood Pressure Education Program Working Group on High Blood Pressure in Pregnancy" (Gifford et al. 2000) was the only one classic document published as document of review in obstetrics and gynecology field with TC2016 of 1,307. Only document type of article was used for further analysis because these classic articles included complete research ideas and results (Ho et al. 2010). As a result, we identified 13 classic articles ( $0.0042 \%$ of 309,377 articles) in category of obstetrics and gynecology. The percentage of classic articles in a research file was lower than medical related topics, for example $0.048 \%$ and $0.063 \%$ of all documents in Web of Science categories of neurosciences (Yeung and Ho 2018) and psychology (Ho and Hartley 2016a).

Only document type of article was considered for further analysis because articles contain description of complete researches and results (Ho et al. 2010). The 13 classic articles were published by 75 authors including 12 first authors.

\section{Effect of time on citation analysis}

A relationship between number of classic articles in a decade (TP) and their citations per publication $(\mathrm{CPPyear}=\mathrm{TCyear} / \mathrm{TP})$ as a figure was proposed to compare publications of classic articles (Ho 2014b). Figure shows the relationship of 13 classic articles in Web of Science category of obstetrics and gynecology. Two classic articles were published in the decades 1970s and 1980s while three were in the 1990s and the 2000s. Figure 1 also shows that the trend in CPP2016 is similar for the classic articles across the decades, but a much higher score occurring in the1950s. There was no any classic articles published during the World War I and II. In addition, the latest classic article was published in 2004. That means 13 years were needed to for an article to accumulate their citations to reach 1,000 in Web of Science category of obstetrics and gynecology.

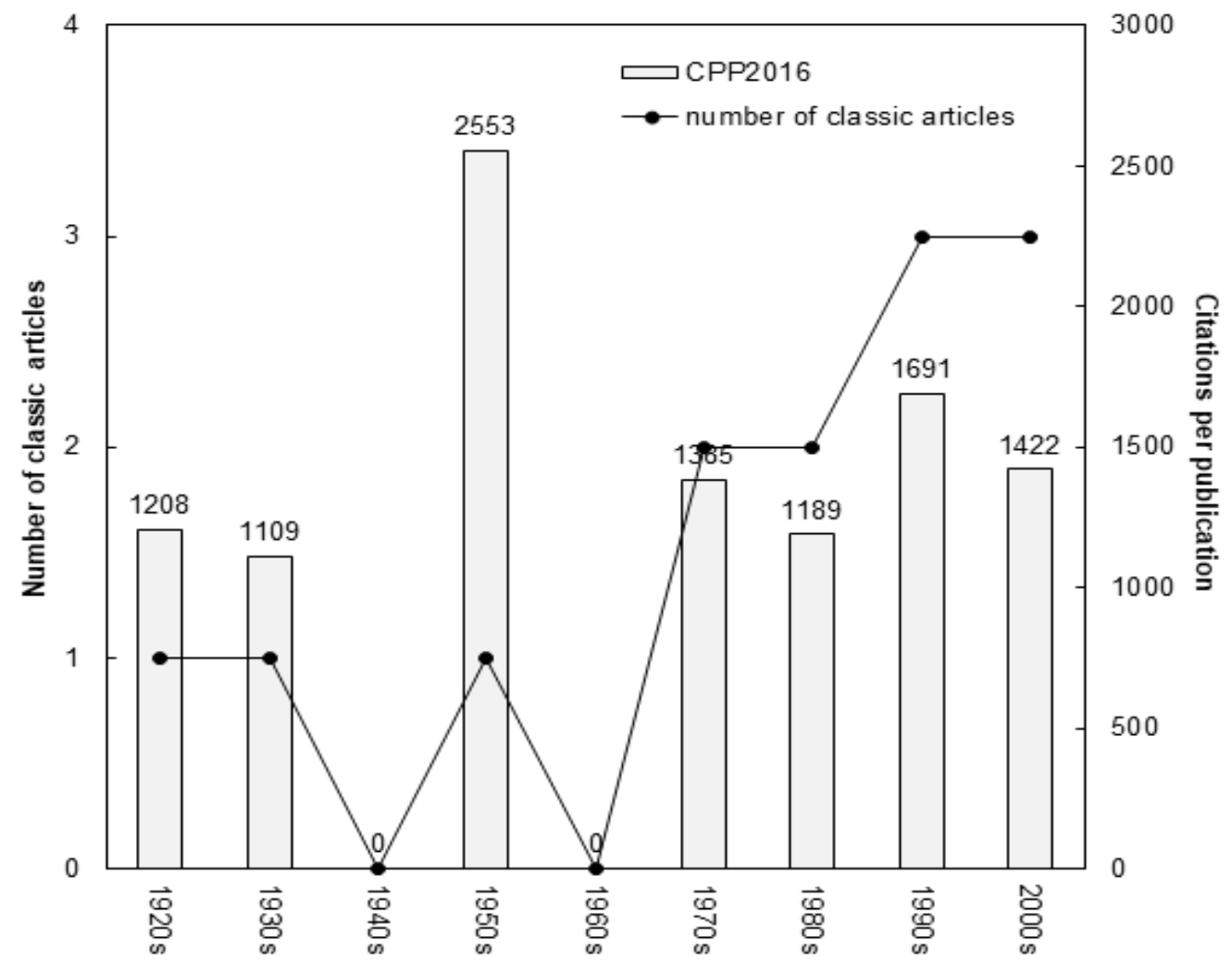

Figure 1: Number of classic articles in Web of Science category of obstetrics and gynecology and citation per article by decades.

\section{Journals}

A total of 81 journals were listed in the Web of Science category of obstetrics and gynecology in 2016. The 13 classic articles were published in six of these journals (7.4\% of 81 journals) and British Journal of Obstetrics and Gynaecology was no longer in Web of Science category of obstetrics and gynecology after 2001. The journal was changed to be BJOG-An International Journal of Obstetrics and Gynaecology with
IF2016 of 4.624 (rank 4th of 81 obstetrics and gynecology journals in 2016). American Journal of Obstetrics and Gynecology with IF2016 of 5.226 (rank 2nd of 81 obstetrics and gynecology journals), published the largest number of classic articles with five articles (38\% of 13 classic articles), followed by Fertility and Sterility (IF2016 $=4.447$; ranked 8th), Human Reproduction (IF2016 = 11.748; ranked 1st), and Obstetrics and Gynecology (IF2016 = 5.215; ranked 3rd), with two. Early Human 
Development (IF2016 = 2.169; ranked 37th) and British Journal of Obstetrics and Gynaecology had only one classic article respectively.

\section{Citation history of classic articles}

Table 1 shows the 13 classic articles in Web of Science category of obstetrics and gynecology with both citation numbers and rankings for TC2016 and C2016. Total citations indicated high impact or visibility of an article in a research field. Due to the citations of publications in Web of Science Core Collection were updated weekly, the total number of times an article cited from its publication to the end of 2016 (TC2016) was used (Wang et al. 2011, Chuang et al. 2011). The advantage of using TC2016 is that they are invariable and ensure repeatability compared with the index of citation from Web of Science Core Collection (Ho and Hartley 2016a).

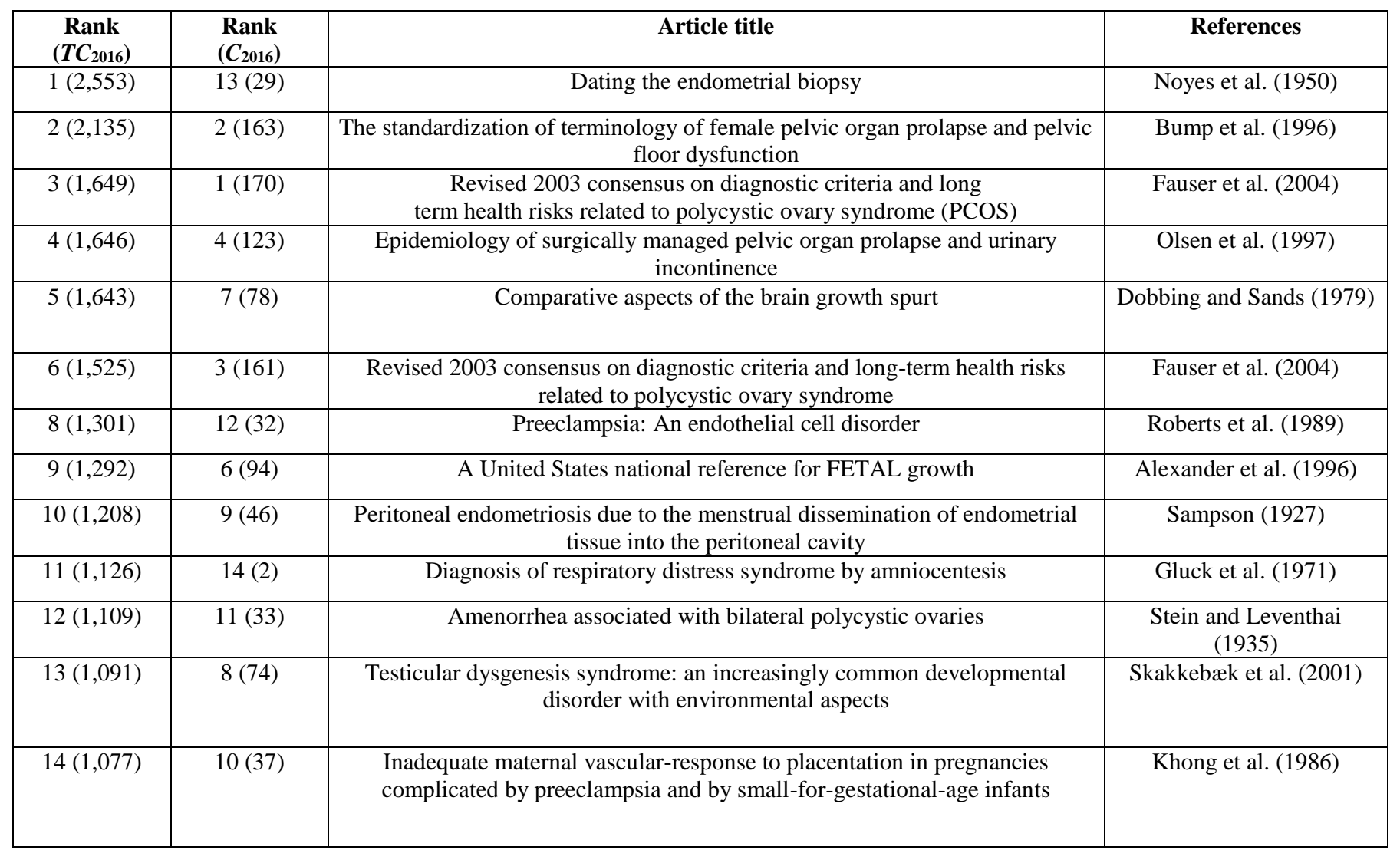

Table 1: The 13 classic articles in Web of Science category of obstetrics and gynecology.

TC2016: total citations from Web of Science Core Collection since publication to the end of 2016; C2016: citations in 2016 only.

The history of a publication's citations with time has long been studied (Avramescu 1979). Today, modern computing techniques have replaced hand-based ones. Thus big data analysis for papers' citation history were presented (Ho 2008; Ho and Kahn 2014; Ho 2018). Citation history shows characteristics of an article impact after publication. The highly cited articles would not always have high impact or visibility in research society (Ho 2014a). Four of the 13 classic articles still have a high C2016 $\geq 100$. Figures 2,3 , and 4 show the citation history of the classic articles that were ranked by TC2016. Although latterly published classic articles within the past decade had great potential, they did not have the top
TC2016. Thus indicator of C2016 would be interesting to show their impact in 2016. A typical example is that article published by Fauser et al. (2004) in 2004 was the most impact classic article in 2016 with C2016 of 170. A sharply increasing trend of citations can be found after its publication. Similarly, article by Chang et al. (2004) had the same impact trend as article by Fauser et al. (2004) in last decade. Article by Gluck et al. (1971) had sharply increasing citations after publication and then had sharply decreasing citations. This classic had less impact in research world. Similarly, Noyes et al. (1950) published the most frequently cited classic article in Web of Science category of obstetrics and gynecology, which had 53 years increasing citations after its publication. However, a trend of decreasing citations was appeared in the last decade. 


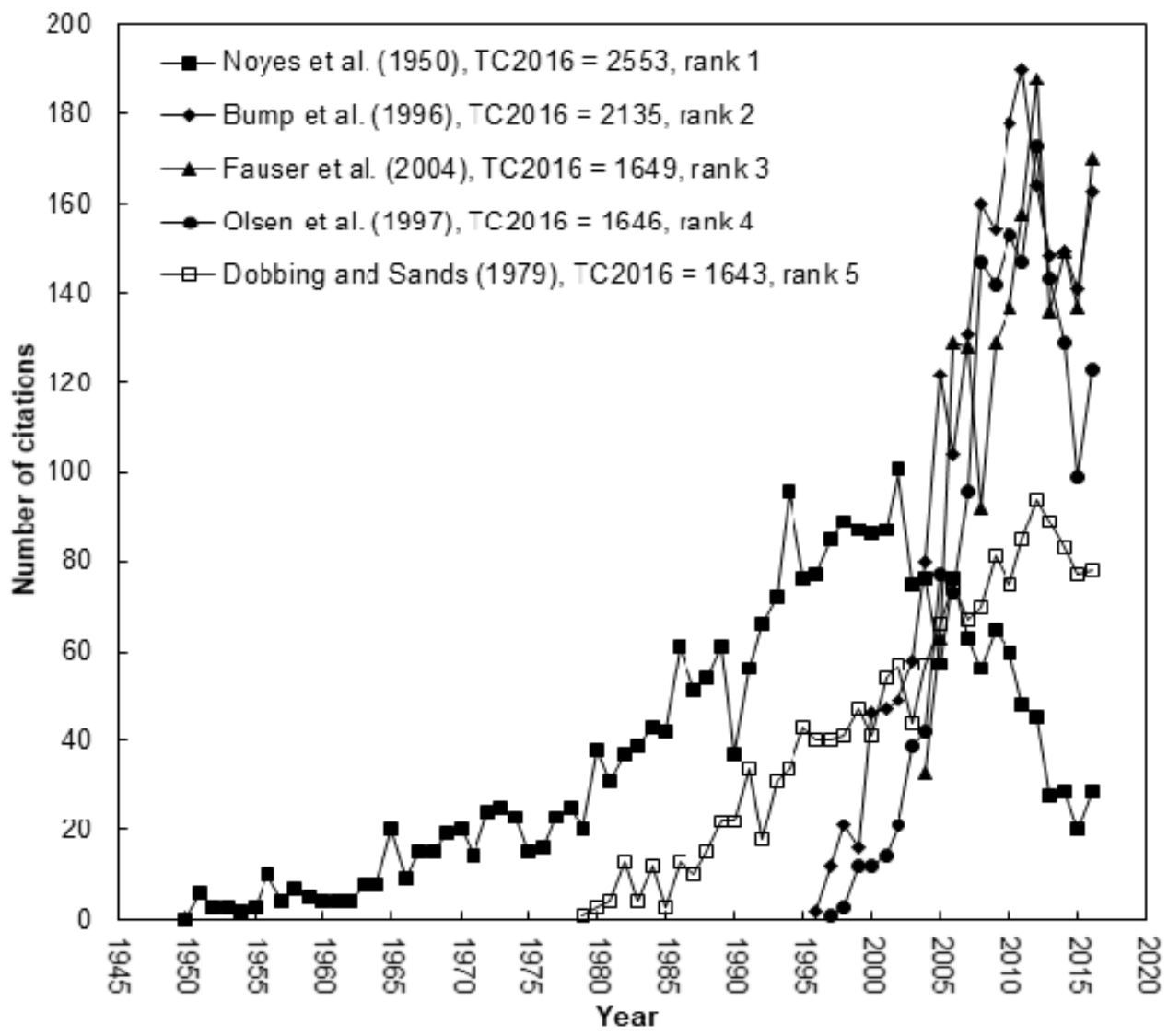

Figure 2: Citation histories of the top five classic articles

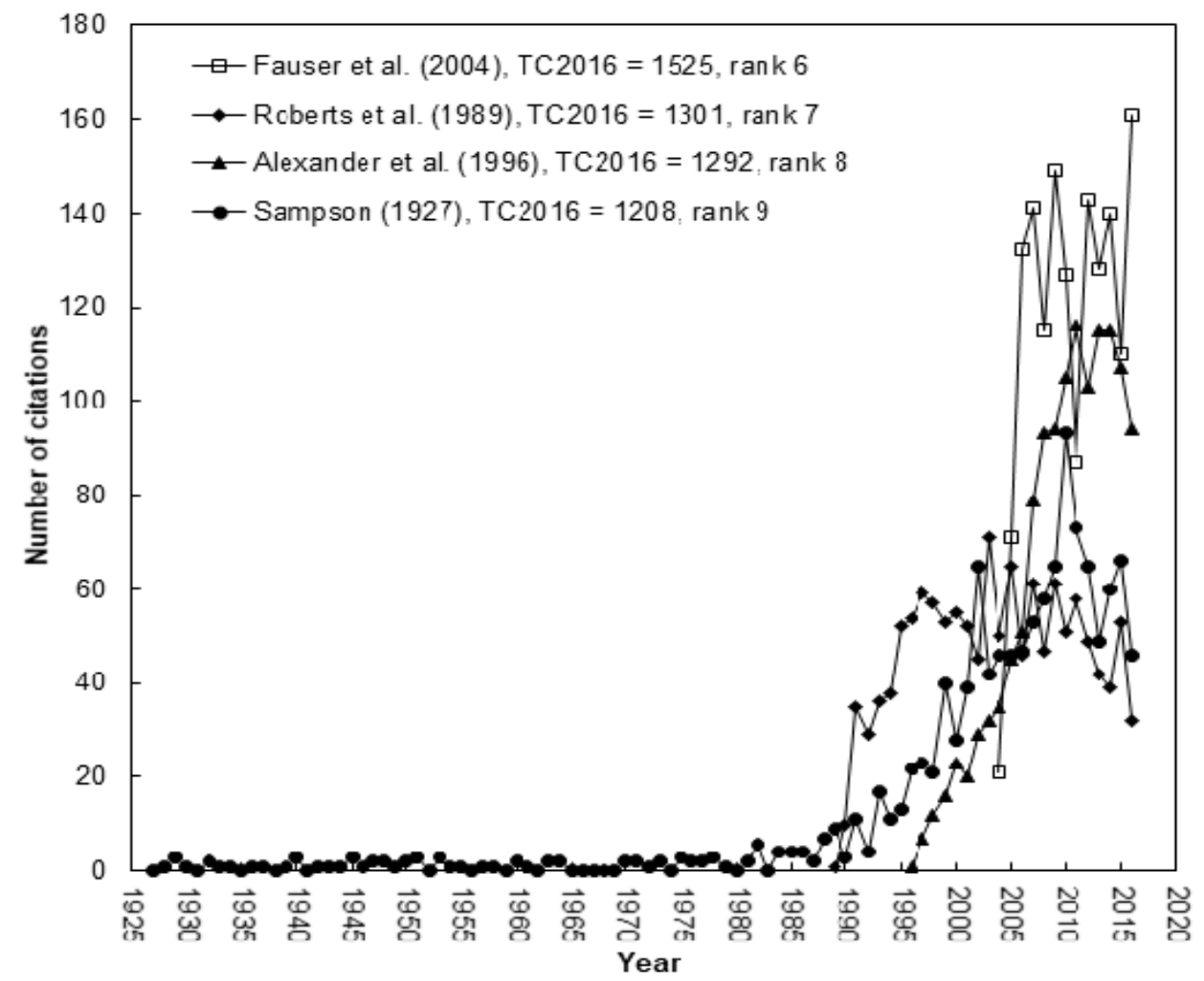




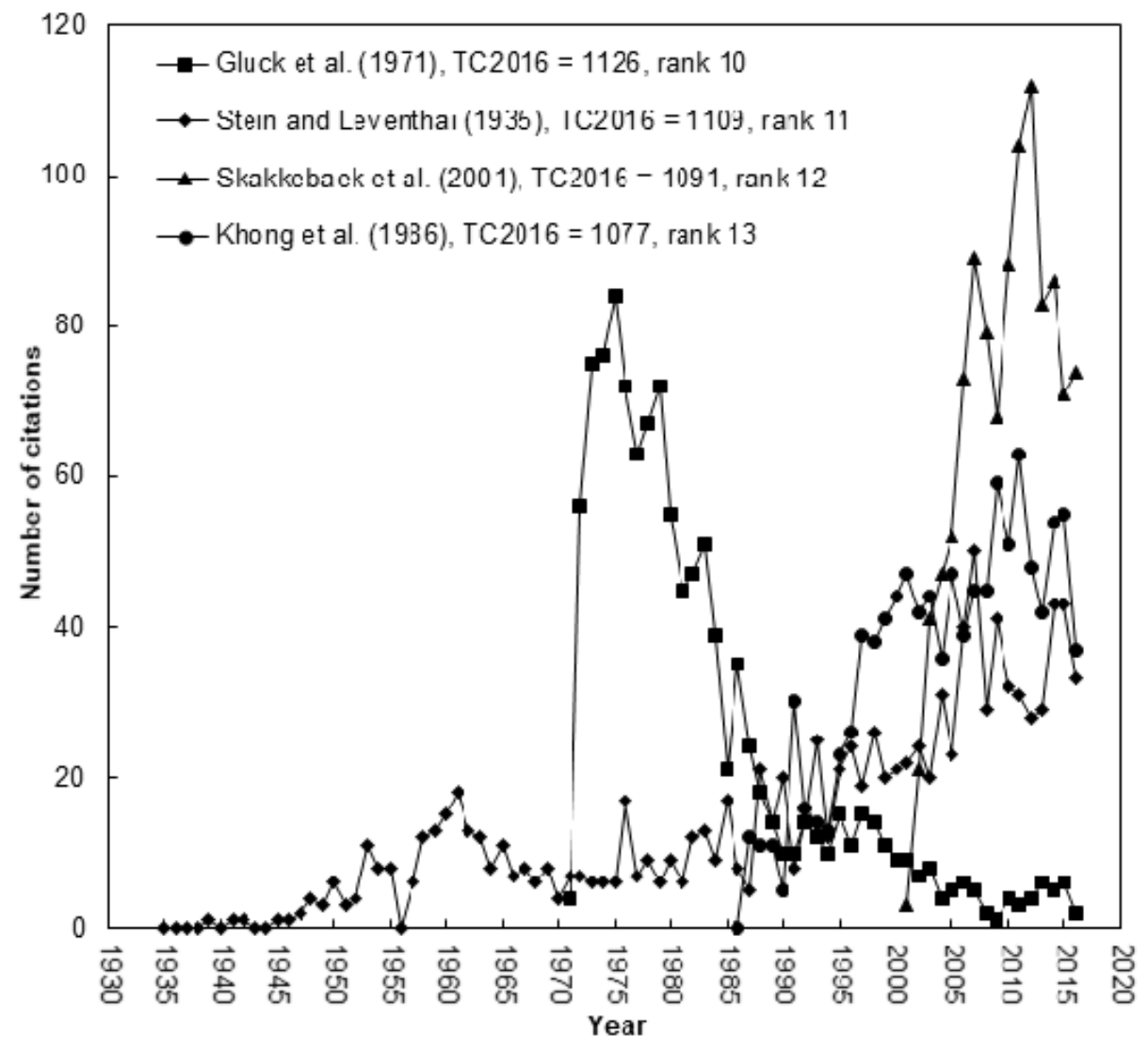

Figure 4: Citation histories of the top 10-13 classic articles

\section{Highlight of the classic articles}

Dating the endometrial biopsy (Noyes et al. 1950)

The classic author, R.W. Noyes from Free Hospital for Women and Harvard Medical School in USA as the first and also corresponding authors with the highest TC2016 of 2,553 in Web of Science category of obstetrics and gynecology.

Endometrial biopsy criteria and usefulness are reviewed in this article. This study aims tolimit the criteria used in dating endometrial biopsies, as current components used are not sufficient enough to provide information on ovulation cycles. Overall, the new criteria, examining the endometrial during the secretory phase in greater detail that dated 300 biopsies correlated with the onset of subsequent menstruation. Of the 300 cases, 40 were correlated with ovulation based by basal body temperature. It also correlated the endometrial biopsy with basal body temperature changes to promote better accurate information of ovulation time, progesterone change during ovulation, and the endometrial biopsy effect on the length of secretory period and menses.

The standardization of terminology of female pelvic organ prolapse and pelvic floor dysfunction (Bump et al. 1996)

The classic author, R.C. Bump from Duke University Medical Center in USA published the classic article as the first and also the corresponding authors with TC2016 of 2,135 and C2016 of 163.

Standardized terminologies on describing female pelvic organ prolapse and pelvic floor dysfunction were approved by the following authority organizations: The International Continence Society, The American Urogynecologic Society, and The Society of Gynecologic Surgeons. The standardized terminologies have promoted the effective communication among caregivers, patients, and academic parties, while performing research interpretation improves care giver quality.

Revised 2003 consensus on diagnostic criteria and long-term health risks related to polycystic ovary syndrome (PCOS) (Fauser et al. 2004)

The most impact classic article in 2016 published by B.C.J.M. Fauser from Center of Reproductive Medicine in Netherlands as the first and also the corresponding authors with the highest C2016 of 170.

Based on the $1990 \mathrm{NIH}$-sponsored conference encompasses broader diagnostic criteria for polycystic ovary syndrome (PCOS) in the 2003 Rotterdam workshop, the article specified that PCOS is an ovarian dysfunction with multiple diagnoses and clinical symptoms. The diagnoses include hyperandrogenism, anovulation, polycystic ovary morphology whose symptoms are menstrual irregularities and insulin resistance. Its long-term health risks include Type II diabetes and cardiovascular disease, etc.; therefore, a single diagnosis is sufficient for clinical diagnosis.

Epidemiology of surgically managed pelvic organ prolapse and urinary incontinence (Olsen et al. 1997)

The classic article was published by A.L. Olsen from University of Iowa Hospitals and Clinics in USA as the first and also the corresponding authors.

The study was held at Kaiser Permanente Northwest, which involved 149,554 women, aged 20 or older. The study analyzed pelvic organ prolapse and urinary incontinence incidences related to age-specific and weight of primary versus repeat surgical procedures for pelvic organ prolapse and urinary incontinence. The result determined $11.1 \%$ lifetime 
risk for a woman to experience at least one operation related to pelvic floor dysfunction.

Comparative aspects of the brain growth spurt (Dobbing and Sands 1979)

The classic article was published by J. Dobbing from University of Manchester in the UK as the first and also the corresponding authors.

Different time periods of brain growth spurts for different species. The different species have different lifetime spans, as well as different growth rates. Species were categorized as prenatal, perinatal, and postnatal periods for the brain growth spurt study. Different time period studies have focused on different aspects that affect brain growth spurts, including species, timing in relation to birth, severity, and proportional duration.

Revised 2003 consensus on diagnostic criteria and long-term health risks related to polycystic ovary syndrome (Fauser et al. 2004)

The classic article was published by B.C.J.M. Fauser from Center of Reproductive Medicine in Netherlands as first author and also the corresponding author. Fauser was the only one who published two classic articles. This classic article was published by the same team as the classic article "Revised 2003 consensus on diagnostic criteria and long-term health risks related to polycystic ovary syndrome (PCOS)" (Fauser et al. 2004).

\section{Preeclampsia: An endothelial-cell disorder (Roberts et al. 1989)}

The classic article was published by J.M. Roberts from University of California, San Francisco in USA as the first and also the corresponding authors.

Preeclampsia was proposed to be more than a clinical evidence of hypertension. There are other characters while preeclampsia occurs: cascade of coagulation, intravascular fluid redistribution, and vasoconstriction. Poor placenta tissue perfusion causes damage to the endothelial cell.

A United States national reference for FETAL growth (Alexander et al. 1996)

The classic article was published by G.R. Alexander from University Alabama in USA as the first and also the corresponding authors.

The research has developed a national fetal growth curve by using birth weight and a completed gestational age. This fetal growth curve will be able to serve as a common reference to predict the consequences of small and large gestational age delivery. A total of 3,88,689 mothers in the U.S. with singleton live births were involved in this study. The data was obtained from the U.S. Live Birth File in 1991, created by the National Center for Health Statistics.

Peritoneal endometriosis due to the menstrual dissemination of endometrial tissue into the peritoneal cavity (Sampson 1927)

This is the only one single author classic article, was published by J.A. Sampson from the Albany Hospital and the Albany Medical College in USA.

It was suggested that possible reasons of peritoneal endometriosis from menstrual blood escape into the peritoneal cavity included the rupture of the endometrial cyst, implantation of endometrial tissue disseminated by menstruation grown on the surface of the ovary and other pelvic structures, back flow from fallopian tube into the uterine cavity, and menstruation of tubal mucosa. This information has clinical benefitspredicting and finding the causes of peritoneal endometriosis to better treat patients.
Diagnosis of respiratory distress syndrome by amniocentesis (Gluck et al. 1971)

The classic article was published by L. Gluck from University of California, San Diego School of Medicine as the first author. The article had much less impact in the recent years.

The most reliable procedure to diagnose fetal lung maturity: the ratio of lecithin/sphingomyelin in amniotic fluid, was concluded. This procedure has become a major clinical method used to identify the readiness of fetus lung maturity. At 35 weeks gestational age, the fetal lecithin concentration will suddenly increase, signing a mature pulmonary alveolar lining; therefore, if the fetus is delivered the chances respiratory distress are kept to a minimum.

Amenorrhea associated with bilateral polycystic ovaries (Stein and Leventhai 1935)

The classic article was published by I.F. Stein from Michael Reese Hospital as the first author.

Bilateral polycystic ovaries were reportedly connected to seven cases of amenorrhea. It was suggested that bilateral polycystic ovaries were not caused by inflammatory changes, but by hormonal factors. Using an estrogenic hormone as a means of treating amenorrhea was not effective. Physiological function was fully restored through surgical treatment, specifically wedge resection of the cystic cortex of the ovaries. After surgery, normal menstruation returned and remained for all subjects. In two cases, pregnancy followed after treatment.

Testicular dysgenesis syndrome: an increasingly common developmental disorder with environmental aspects (Skakkebæk et al. 2001)

The classic article was published by N.E. Skakkebæk from Copenhagen University Hospital in Denmark as the first author and also the corresponding authors. This classic article is also belong to document type of proceedings paper.

Due to the increasing demand of assisted reproduction and growing evidence of adverse trends from male reproduction, this article has reviewed hypotheses supporting the new concept of Testicular Dysgenesis Syndrome (TDS). By reviewing multiple evidence studies from different specialities such as evidence from animal and wildlife studies and human experience, it is shown that TDS has become more prevalent-possibly due to environmental or lifestyle influences. The symptoms of TDS includes poor semen quality, testis cancer, undescended testis, and hypospadias. When the syndrome occurs, there is often a combination of these problems seen in one individual.

Inadequate maternal vascular-response to placentation in pregnancies complicated by preeclampsia and by small-for-gestational-age infants (Khong et al. 1986)

The classic article was published by T.Y. Khong from St George's Hospital Medical School in the UK as the first author and also the corresponding authors.

This research examined physiological changes of the placental bed in preeclampsia and small-for-gestational age infants (SGA). Based on an observation in a study of basal plates of placentas, findings pointed to a defect in placental bed spiral arteries and the interaction between migratory trophoblasts and maternal uterine tissues. The study has also confirmed possible reasons of inadequate maternal vascular response to placentation in pregnancies.

3.6. Classic Sleeping Beauties in Web of Science category of obstetrics and gynecology

A 'sleeping beauty' is a term that is often used to describe a research article that remains relatively uncited for several years and then suddenly 
blossoms forward (Ho and Hartley 2016a). van Raan (2004) defined the three characteristics of "sleeping beauties" to be depth of sleep, length of sleep, and awakening intensity.

1. the depth of sleep, where an article receives at most one citation on average per year (deep sleep), or between one to two citations per year during a specific period (less deep sleep);

2. the length of sleep - the duration of the above period; and

3. the intensity of the wakeup period: the number of citations per year for four years following the sleeping period. Furthermore, long sleep and high impact sleeping beauties were also discussed (Ho and Hartley 2017).

Figure 3 shows typical citation curves for the classic Sleeping Beauty in Web of Science category of obstetrics and gynecology. The Sleeping Beauty "Peritoneal endometriosis due to the menstrual dissemination of endometrial tissue into the peritoneal cavity" (Sampson 1927) had an average citation per year of 1.0 in the 18 years as deep sleep and an average citation per year of 2.0 in the 67 years as less deep sleep. After such sleep (67 years) however, the annual citations increased slightly for another decade and reached a plateau in the last ten years (Fig. 3).

\section{Conclusion}

According to citations from Web of Science Core Collection, 14 classic publications including one review, with TC2016 $\geq 1,000$ were found in Web of Science category of obstetrics and gynecology from 1927 to 2004. The largest number of classic articles was published in the last two decades, while the highest citations per publication was found in the 1950s. Five of 13 classic articles were published in American Journal of Obstetrics and Gynecology. The most frequently cited article was published by authors in USA while the most high impact article in 2016 was published by authors in Netherlands. Results from citation histories and citation indicator $\mathrm{C} 2016$ pointed that four of 13 classic articles are continuing to influence related research in recent years with C2016>100. A classic Sleeping Beauties in Web of Science category of obstetrics and gynecology was found with a long less sleep for about seven decades. In addition, the highlight of these classic articles might be usefulness as information for researchers.

\section{References}

1. Alexander, G.R., Himes, J.H., Kaufman, R.B., Mor, J., \& Kogan, M. (1996). A United States national reference for fetal growth. Obstetrics and Gynecology, 87 (2), 163-168.

2. Avramescu, A. (1979). Actuality and obsolescence of scientific literature. Journal of the American Society for Information Science, 30 (5), 296-303.

3. Bump, R.C., Mattiasson, A., Bo, K., Brubaker, L.P., DeLancey, J.O.L., Klarskov, P., Shull, B.L., \& Smith, A.R.B. (1996). The standardization of terminology of female pelvic organ prolapse and pelvic floor dysfunction. American Journal of Obstetrics and Gynecology, 175 (1), 10-17.

4. Chang, J., Azziz, R., Legro, R., Dewailly, D., Franks, S., Tarlatzis, B.C., Fauser, B., Balen, A., Bouchard, P., Dahlgren, E., Devoto, L., Diamanti, E., Dunaif, A., Filicori, M., Homburg, R., Ibanez, L., Laven, J., Magoffin, D., Nestler, J., Norman, R.J., Pasquali, R., Pugeat, M., Strauss, J., Tan, S., Taylor, A., Wild, R., Wild, S., Ehrmann, D., \& Lobo, R. (2004). Revised 2003 consensus on diagnostic criteria and long-term health risks related to polycystic ovary syndrome. Fertility and Sterility, 81 (1), 19-25.

5. Chiu, W.T., \& Ho, Y.S. (2005). Bibliometric analysis of homeopathy research during the period of 1991 to 2003. Scientometrics. 63 (1): 3-23.

6. Chuang, K.Y., Wang, M.H., \& Ho, Y.S. (2011). High-impact papers presented in the subject category of water resources in the
Essential Science Indicators database of the Institute for Scientific Information. Scientometrics. 87 (3): 551-562.

7. Dobbing, J., \& Sands, J. (1979). Comparative aspects of the brain growth spurt. Early Human Development. 3 (1): 79-83.

8. Fauser, B.C.J.M., Chang, J., Azziz, R., Legro, R., Dewailly, D., Franks, S., Tarlatzis, B.C., Fauser, B., Balen, A., Bouchard, P., Dahlgren, E., Devoto, L., Diamanti, E., Dunaif, A., Filicori, M., Homburg, R., Ibanez, L., Laven, J., Magoffin, D., Nestler, J., Norman, R.J., Pasquali, R., Pugeat, M., Strauss, J., Tan, S., Taylor, A., Wild, R., Wild, S., Ehrmann, D., \& Lobo, R. (2004). Revised 2003 consensus on diagnostic criteria and long-term health risks related to polycystic ovary syndrome (PCOS). Human Reproduction. 19 (1): 41-47.

9. Garfield, E. (1976). Highly cited articles. 26. Some classic papers of late 19th and early 20th centuries. Current Contents. 21: 5-9.

10. Gifford, R.W., August, P.A., Cunningham, G., Green, L.A., Lindheimer, M.D., McNellis, D., Roberts, J.M., Sibai, B.M., \& Taler, S.J. (2000). Report of the National High Blood Pressure Education Program Working Group on High Blood Pressure in Pregnancy. American Journal of Obstetrics and Gynecology, 183 (1), S1-S22.

11. Gluck, L., Kulovich, M.V., Borer, R.C., Brenner, P.H., Anderson, G.G., \& Spellacy, W.N. (1971). Diagnosis of respiratory distress syndrome by amniocentesis. American Journal of Obstetrics and Gynecology, 109 (3), 440-445.

12. Hartley, J., \& Ho, Y.S. (2017). Who woke the sleeping beauties in psychology? Scientometrics, 112 (2), 1065-1068.

13. Ho, Y.S. (2008). Bibliometric analysis of biosorption technology in water treatment research from 1991 to 2004. International Journal of Environment and Pollution. 34 (1-4): 1-13.

14. Ho, Y.S. (2012). Top-cited articles in chemical engineering in Science Citation Index Expanded: A bibliometric analysis. Chinese Journal of Chemical Engineering. 20 (3): 478-488.

15. Ho, Y.S. (2014a). A bibliometric analysis of highly cited articles in materials science. Current Science, 107 (9), 1565-1572.

16. Ho, Y.S. (2014b). Classic articles on social work field in Social Science Citation Index: A bibliometric analysis. Scientometrics, 98 (1), 137-155.

17. Ho, Y.S. (2018). Classic papers published by Taiwanese scientists in the science citation index expanded: A bibliometric study. COLLNET Journal of Scientometrics and Information Management, 12 (1), 83-95.

18. Ho, Y.S., \& Fu, H.Z. (2016). Mapping of metal-organic frameworks publications: A bibliometric analysis. Inorganic Chemistry Communications, 73, 174-182.

19. Ho, Y.S., \& Hartley, J. (2016a). Classic articles in psychology in the Science Citation Index Expanded: A bibliometric analysis. British Journal of Psychology, 107 (4), 768-780.

20. Ho, Y.S., \& Hartley, J. (2016b). Classic articles published by American scientists (1900-2014): A bibliometric analysis. Current Science. 111 (7): 1156-1165.

21. Ho, Y.S., \& Kahn, M. (2014). A bibliometric study of highly cited reviews in the Science Citation Index Expanded ${ }^{\mathrm{TM}}$. Journal of the Association for Information Science and Technology. 65 (2): 372385.

22. Ho, Y.S., Satoh, H., \& Lin, S.Y. (2010). Japanese lung cancer research trends and performance in Science Citation Index. Internal Medicine, 49 (20), 2219-2228.

23. Hsieh, W.H., Chiu, W.T., Lee, Y.S., \& Ho, Y.S. (2004). Bibliometric analysis of patent ductus arteriosus treatments. Scientometrics. 60 (2): 205-215.

24. Khong, T.Y., Dewolf, F., Robertson, W.B., \& Brosens, I. (1986). Inadequate maternal vascular-response to placentation in pregnancies complicated by preeclampsia and by small-for- 
gestational-age infants. British Journal of Obstetrics and Gynaecology. 93 (10): 1049-1059.

25. Levitt, C., Katz, A., Mang, E., \& Safarov, A. (2015). Ten most notable family medicine research studies in Canada. Canadian Family Physician, 61 (6), 523-527.

26. Li, Z., \& Ho, Y.S. (2008). Use of citation per publication as an indicator to evaluate contingent valuation research. Scientometrics, 75 (1), 97-110.

27. Long, X., Huang, J.Z., \& Ho, Y.S. (2014). A historical review of classic articles in surgery field. American Journal of Surgery, 208 (5), 841-849.

28. Noyes, R.W., Hertig, A.T., \& Rock, J. (1950). Dating the endometrial biopsy. Fertility and Sterility. 1 (1): 3-25.

29. Olsen, A.L., Smith, V.J., Bergstrom, J.O., Colling, J.C., \& Clark, A.L. (1997). Epidemiology of surgically managed pelvic organ prolapse and urinary incontinence. Obstetrics and Gynecology, 89 (4), 501-506.

30. Picknett, T., \& Davis, K. (1999). The 100 most-cited articles from JMB. Journal of Molecular Biology. 293 (2): 173-176.

31. Roberts, J.M., Taylor, R.N., Musci, T.J., Rodgers, G.M., Hubel, C.A., \& Mclaughlin, M.K. (1989). Preeclampsia: An endothelial cell disorder. American Journal of Obstetrics and Gynecology, 161 (5), 1200-1204.
32. Sampson, J.A. (1927). Peritoneal endometriosis due to the menstrual dissemination of endometrial tissue into the peritoneal cavity. American Journal of Obstetrics and Gynecology, 14, 422469.

33. Skakkebæk, N.E., Rajpert-De Meyts, E., \& Main, K.M. (2001). Testicular dysgenesis syndrome: An increasingly common developmental disorder with environmental aspects. Human Reproduction, 16 (5), 972-978.

34. Smith, D.R. (2008). Citation indexing and highly cited articles in the Australian Veterinary Journal. Australian Veterinary Journal, 86 (9), 337-339.

35. Stein, I.F., \& Leventhai, M.L. (1935). Amenorrhea associated with bilateral polycystic ovaries. American Journal of Obstetrics and Gynecology, 29, 181-191.

36. van Raan, A.F.J. (2004). Sleeping Beauties in science. Scientometrics, 59 (3), 467-472.

37. Wang, M.H., Fu, H.Z., \& Ho, Y.S. (2011). Comparison of universities' scientific performance using bibliometric indicators. Malaysian Journal of Library \& Information Science, 16(2); 1-19.

38. Yeung, A.W.K., \& Ho, Y.S. (2018). Identification and analysis of classic articles and sleeping beauties in neurosciences. Current Science, 114 (10), 2039-2044.
This work is licensed under Creative Commons Attribution 4.0 License

To Submit Your Article Click Here: Submit Manuscript

DOI: $10.31579 / 2768-0487 / 040$
Ready to submit your research? Choose Auctores and benefit from:

$>$ fast, convenient online submission

$>$ rigorous peer review by experienced research in your field

$>$ rapid publication on acceptance

$>$ authors retain copyrights

$>$ unique DOI for all articles

$>$ immediate, unrestricted online access

At Auctores, research is always in progress.

Learn more auctoresonline.org/journals/journal-of-clinical-andlaboratory-research 